\title{
Evidence for a Single Locus Controlling Flesh Color, Senescent Leaf Color, and Hypanthium Color in Peach
}

\author{
Joshua D. Williamson, Cameron P. Peace, Frederick A. Bliss, David T. Garner, and \\ Carlos H. Crisosto \\ University California, Davis, Kearney Agricultural Center, 9240 S. Riverbend Avenue, Parlier, \\ CA 93648-9774
}

\begin{abstract}
AdDITIONAL INDEX WORDs. carotenoids, colorimetry, co-segregation, inheritance, pleiotropy
Abstract. The $Y$ locus of peach [Prunus persica (L.) Batsch] controls whether a tree will produce fruit with white or yellow flesh. Flesh color has implications for consumer acceptance and nutritional quality, and improved cultivars of both flesh types are actively sought. This paper focuses on evidence that the flesh color locus also controls senescent leaf color (easily observed in the fall) and hypanthium color. In two progeny populations totaling 115 progeny plus their parents, the three traits co-segregated completely. Trees carrying the dominant allele for white flesh had yellow senescent leaves and yellow hypanthia, while homozygous recessive yellow-fleshed types exhibited orange senescent leaves and orange hypanthia. Senescent leaf color was also measured quantitatively, with major colorimetric differences observed between white-fleshed and yellow-fleshed progeny. Senescent leaf hue angle and reflected light wavelengths of 500 to $560 \mathrm{~nm}$ were the parameters most affected by the flesh color locus. Results were verified with 10 white-fleshed and 10 yellow-fleshed cultivars. The findings show that the $Y$ locus in peach controls the type and concentration of carotenoids in multiple organs, including fruit, leaves, and flowers. The ability to discriminate between white and yellow flesh color using a simple visual method, applicable in plants not yet at reproductive maturity, is valuable to breeders wanting to save time, growing space, and money.
\end{abstract}

Both yellow- and white-flesh peaches have been grown for thousands of years, with origins rooted in China (Schery, 1972). Currently, improved yellow-fleshed cultivars dominate the U.S. market, however, nearly $30 \%$ of the peaches and nectarines grown in California are white-fleshed types (USDA, 2005). The color of peach and nectarine (Prunus persica) fruit flesh has important implications for nutritional quality, particularly in terms of carotenoid levels (Gil et al., 2002). Flesh color is controlled by a single locus $(Y)$, with white flesh dominant over yellow flesh (Bailey and French, 1949; Connors, 1919). Cultivars with orange flesh also occur extensively in canning cling peach germplasm. Red flesh, such as in 'Indian Cling', is probably controlled by a separate locus (Okie, 1998). Quantitative differences in color between cultivars of yellow fruit, as well as the existence of other flesh colors, may reflect a more complex control of the trait by the $Y$ locus and/or the action of other loci.

During senescence of leaves in the fall, after chlorophyll has degraded, the underlying color due to other pigments can be observed in leaves (Bliss et al., 2002). Senescent leaf color, which can be yellow or orange, segregates as a simple monogenic trait where yellow is dominant over orange, named LFCLR (Bliss et al., 2002; although the report incorrectly noted orange as dominant to yellow). This locus was mapped to peach linkage group 1, in the same vicinity as where other researchers have mapped the $Y$ locus (Bliss et al., 2002). However, a lack of fruit set precluded mapping $Y$ in the same population as $L F C L R$, to verify that the traits are controlled by the same locus (Bliss et al., 2002). Moore (1948) examined 612 genotypes for fruit flesh and leaf color using a Dictionary of Color as a guide to the different colors. Although Moore (1948) included 525 seedlings, parentage was not considered, and therefore segregation patterns could not be

Received for publication 23 Nov. 2004. Accepted for publication 14 Oct. 2005. To whom reprint requests should be addressed. E-mail cpeace@uckac.edu. compared. Color of the inside of the calyx cup, or hypanthium, of peach flowers has also been associated with flesh color, and is suggested to segregate in a codominant fashion (Connors, 1919). Confirmation is required on whether either trait could provide a useful proxy for flesh color in breeding programs.

The present study was conducted to determine whether $Y$ and $L F C L R$ represent the same locus, and if hypanthium color is also associated, by examining the segregation of each qualitative trait in the same population. Senescent leaf color was also measured with a colorimeter, to quantify the difference between "yellow" and "orange" and determine whether it has a more complex inheritance.

\section{Materials and Methods}

Plant material. Four sets of germplasm were used: "Parents" (white-fleshed cultivar Georgia Belle and yellow-fleshed cultivar Dr. Davis); "Pop-DG" [51 $\mathrm{F}_{1}$ progeny of 'Dr. Davis' and 'Georgia Belle', segregating 1:1 for flesh color (26 white-fleshed and 25 yellow-fleshed progeny)]; "Pop-G" [64 progeny derived from selfing 'Georgia Belle', segregating 3:1 for flesh color (49 whitefleshed and 15 yellow-fleshed progeny)]; and "Cultivars" [10 white-flesh cultivars ('Babcock', 'Giant Babcock', 'Gold Mine', 'Heavenly White', 'Melba', 'Polly', 'Snow Flame', 'Stanwick', 'Strawberry', and 'White Lady') and 10 yellow-flesh cultivars ('Carnival', 'Elegant Lady', 'Fay Elberta', 'Flavorcrest', 'J.H. Hale', 'Maycrest', 'OHenry', 'Queenscrest', 'Spring Lady', and 'Zee Lady')]. Two trees represented each individual genotype for the Parents, Pop-DG, and Pop-G germplasm sets. In the case of Pop-DG and Pop-G, one tree was the scion on its own roots, while the other tree was the scion on the commercial rootstock cultivar, 'Nemaguard'. The two trees for each of the Parents were grown on the 'Nemaguard' rootstock. White-flesh vs. yellow-flesh phenotype was determined by observation of fruit in previous 
seasons for Parents, Pop-DG, and Pop-G, and according to Okie (1998) for Cultivars (although 'Giant Babcock' is erroneously listed as yellow-fleshed in that publication). In addition, the redfleshed cultivar Indian Free was included.

Trait measurements. For two consecutive years, the color of senescing leaves was qualitatively assessed during the fall season. Each tree was noted for whether it displayed yellow leaves or orange leaves. During the second year, quantitative assessment of senescent leaf color was also performed. For each tree, five leaves were collected that displayed a solid consistent color, avoiding leaves with patches of green or red. Moore (1948) attributed these patches that are observed in senescing leaves to high vigor (i.e., greenish yellow patches) or low vigor (i.e., reddish/brownish patches), a source of variation that should be avoided because of the masking effect it has on yellow/orange pigments. Over-exposure to bright sunlight also leads to the development of a reddish overcolor, which is comparable to low vigor (Moore, 1948). Leaves were collected over a 1-week period with each tree harvested when at least $25 \%$ of its leaves displayed a consistent senescent color (i.e., had turned from green to its fall color). During the same week, leaves from the parents were repeatedly collected, once each day that leaves of their progeny were collected. Leaves were then immediately brought to the laboratory, where they were cleaned with dampened paper towels to remove dust, and placed individually on a white porcelain tile for colorimetric analysis using a BYK-Gardner color guide 45/0 (BYK-Gardner, Columbia, Md.). The parameters of lightness $\left(\mathrm{L}^{*}\right)$, chroma $\left(\mathrm{C}^{*}\right)$, hue angle $\left(\mathrm{h}^{\circ}\right)$, and reflectance values for 400 to $700 \mathrm{~nm}$ wavelengths at $20-\mathrm{nm}$ intervals, were recorded in one measurement per leaf. At anthesis in the spring of the third year, the color of the inside of the flower calyx cup (hypanthium) was visually assessed and scored for all germplasm.

Data ANALYSIS. Analysis of variance (ANOVA) was conducted separately for each germplasm set, testing the effects of flesh color (white versus yellow), genotype (not Parents), date (Parents only), rootstock (Pop-DG and Pop-G only), and all relevant twoway interactions, using the GLM procedure of SAS (version 8.0; SAS Institute, Cary, N.C.). Shapiro-Wilk normality tests were conducted with Analyse-it (version 1.71; Analyse-it Software Ltd., Leeds, U.K.).

\section{Results}

From qualitative assessment, individuals with white-fleshed fruit always exhibited yellow senescent leaf color and yellow hypanthia, while yellow fruit flesh was always associated with orange senescent leaf color and orange hypanthia (Table 1). No recombinants were observed in 137 individuals from the four sets of germplasm. Visual differences between "orange" and "dark orange" senescent leaves were not consistent between progeny, and appeared to be more related to degree of senescence. Green hypanthia were observed only in undeveloped flowers, even in those that would eventually turn dark orange. The red-fleshed cultivar Indian Free had yellow senescent leaves and hypanthia.

Senescent leaf hue angle was the parameter most significantly affected by flesh color (Fig. 1). Leaves from white-fleshed trees had average hue angles of $\approx 86$ to 87 - "yellow" according to the CIELAB diagram (Voss, 1992) - while hue angle for yellow-fleshed individuals averaged 73 to 75 - "orange-yellow." Distributions of leaf hue angle for white- and yellow-fleshed individuals were distinct and without overlap for all germplasm sets (Fig. 2). All four germplasm sets also had very similar ranges
Table 1. Number of peach genotypes observed for four fruit flesh and senescent leaf color combinations, across four germplasm sets.

\begin{tabular}{lcccc}
\hline $\begin{array}{l}\text { Flesh color } \\
\text { Leaf color }\end{array}$ & $\begin{array}{c}\text { White } \\
\text { Yellow }\end{array}$ & $\begin{array}{c}\text { Yellow } \\
\text { Orange }\end{array}$ & $\begin{array}{c}\text { White } \\
\text { Orange }\end{array}$ & $\begin{array}{c}\text { Yellow } \\
\text { Yellow }\end{array}$ \\
\hline Germplasm set & Genotypes & (no.) & \\
Parents & 1 & 1 & 0 & 0 \\
Cultivars & 10 & 10 & 0 & 0 \\
Pop-DG & 26 & 25 & 0 & 0 \\
Pop-G & 49 & 15 & 0 & 0 \\
Total & 86 & 51 & 0 & 0 \\
\hline
\end{tabular}

zParents $=$ white-fleshed cultivar Georgia Belle and yellow-fleshed cultivar Dr. Davis; Cultivars $=10$ white-fleshed cultivars and 10 yellow-fleshed cultivars; Pop-DG $=51 \mathrm{~F}_{1}$ progeny of 'Dr. Davis' $\mathrm{x}$ 'Georgia Belle' ; Pop-G $=64$ progeny from selfing 'Georgia Belle'.

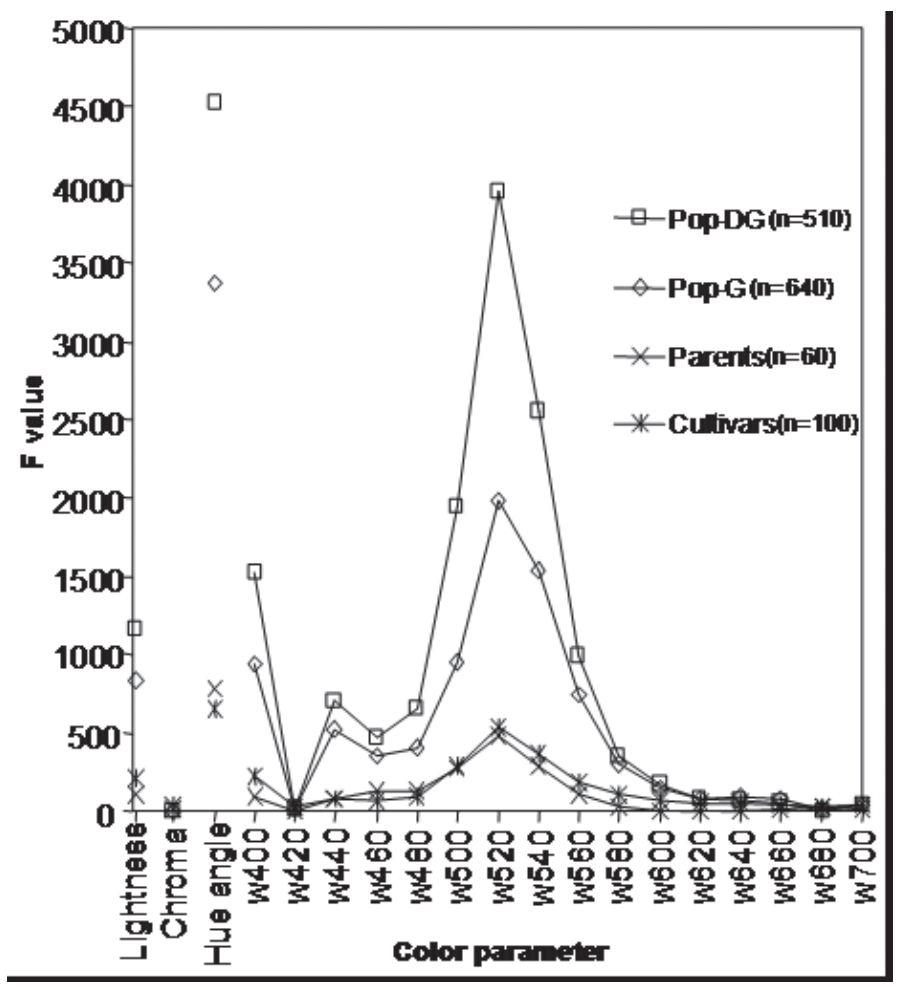

Fig. 1. F values obtained from ANOVA for the effect of the $Y$ locus on various quantitative measures of color for fall leaves in four peach germplasm sets. Lightness, chroma, and hue angle represent the three parameters of the $\mathrm{L}^{*} \mathrm{C}^{*}$ $\mathrm{h}^{\circ}$ color system (Voss, 1992). The parameters of w400 to w700 represent light wavelengths from $400 \mathrm{~nm}$ to $700 \mathrm{~nm}$. Parents = white-fleshed cultivar Georgia Belle and yellow-fleshed cultivar Dr. Davis; Cultivars $=10$ white-fleshed cultivars and 10 yellow-fleshed cultivars; Pop-DG $=51 \mathrm{~F}_{1}$ progeny of 'Dr. Davis' $\mathrm{x}$ 'Georgia Belle;' Pop-G = 64 progeny from selfing 'Georgia Belle'.

of hue angles (on an individual leaf basis): 66 to 81 for yellow flesh and 81 to 91 for white flesh (Fig. 2). An even greater separation between white- and yellow-fleshed genotypes was observed when hue angle averages for individual trees were considered (results not shown). As recorded for the visual assessment, there were no discernable quantitative differences between light orange and dark orange leaves, with the hue angles of all orange leaves appearing as simple Normal distributions for each germplasm set (Fig. 2; $P$ $>0.05$ with the Shapiro-Wilk normality test). Some minor peaks were observed in the distributions, but were not critical since the variation within the leaves of the parents covered the entire ranges seen in their progeny, as well as within the cultivars, which also included such peaks. Leaves of the red-fleshed cultivar Indian 

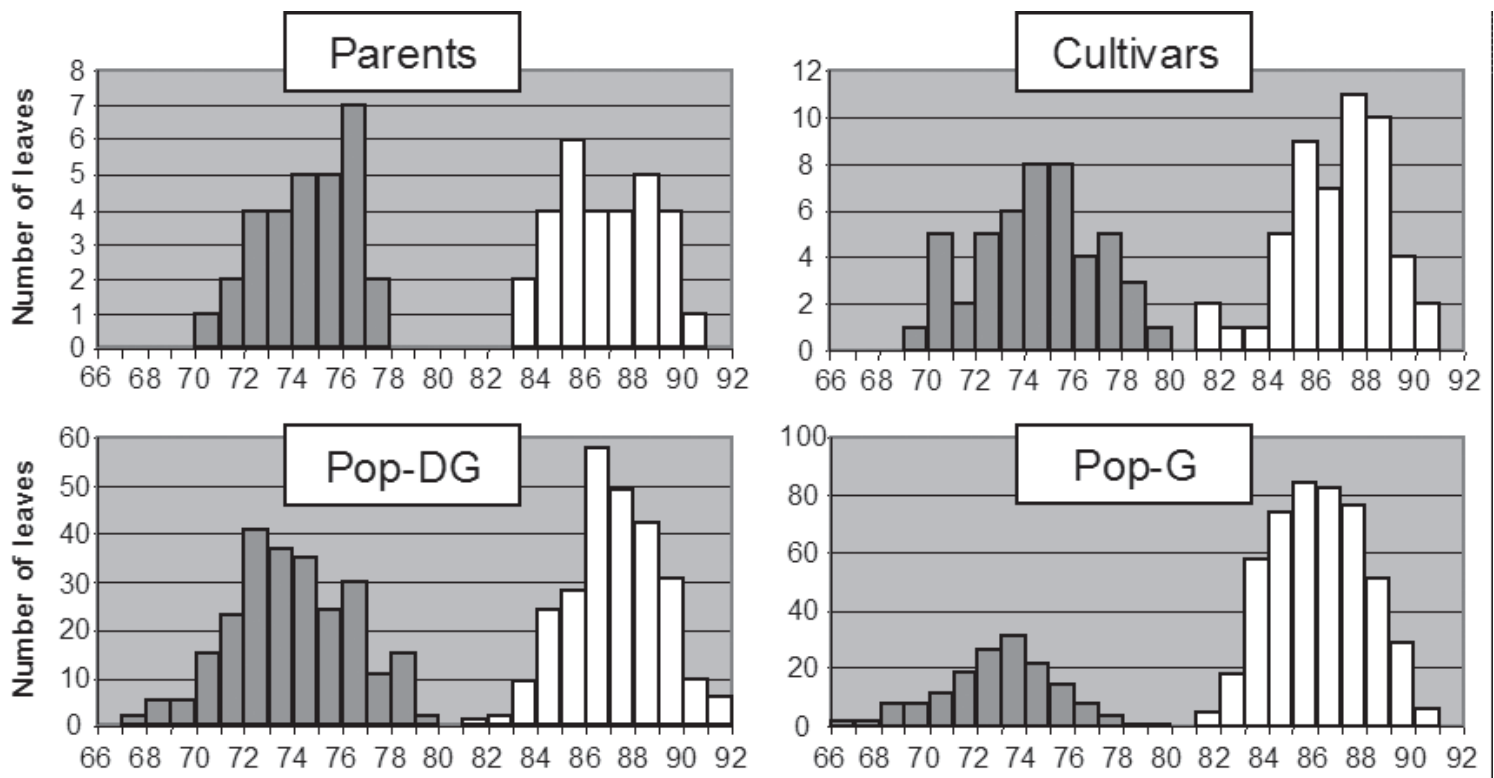

Hue angle

yellow-fleshed $\square$ white-fleshed

Hue angle

Fig. 2. Distributions of hue angle for leaves collected in fall from four peach germplasm sets. Visually, a hue angle of $\approx 66$ appeared as dark orange, $\approx 73$ as orange, $\approx 80$ as very light orange, $\approx 87$ as yellow, and $\approx 92$ as light yellow. Pop-G exhibited a 1:3 segregation pattern as it was derived from the selfing of a cultivar heterozygous at the $Y$ locus. Parents = white-fleshed cultivar Georgia Belle and yellow-fleshed cultivar Dr. Davis; Cultivars $=10$ white-fleshed cultivars and 10 yellow-fleshed cultivars; Pop-DG = 51 F progeny of 'Dr. Davis' $x$ ‘Georgia Belle'; Pop-G $=64$ progeny from selfing 'Georgia Belle'.

Free had hue angles of 89 to 92 , which were at the far end of the range for white-fleshed cultivars. The reflected light wavelengths that were most influenced by the $Y$ locus ranged from $500 \mathrm{~nm}$ to $560 \mathrm{~nm}$ - particularly $520 \mathrm{~nm}$, which was almost as significantly affected as the hue angle for each germplasm set (Fig. 1). Highly significant correlation was found to exist between hue angle and reflectance at $520 \mathrm{~nm}(0.967, P<0.0001)$. Around this reflectance value, there was a considerably higher reflectance for white- over yellow-fleshed genotypes in all germplasm sets (Fig. 3). The red-fleshed cultivar had reflectance values that most closely followed those of white-fleshed individuals; however, the values were significantly higher for wavelengths of $\approx 440$ to $540 \mathrm{~nm}$ (Fig. 3).

After flesh color, genotype (i.e., the combined effect of all genes of an individual) was the next most significant factor affecting senescent leaf color (Table 2), with some genotypes (cultivars or progeny) tending to have higher hue angles than others. This effect was observed for all germplasm, and also when ANOVA was performed only within white-fleshed or within yellowfleshed individuals. Within white-fleshed individuals, genotypic variation was not enough to cause leaf color to qualitatively or quantitatively appear as orange. Likewise, even the most extreme genotypes amongst yellow-fleshed individuals did not have yellow leaves. Other statistically significant factors were relatively minor (Table 2). Although the hue angle of yellow and orange leaves responded differently to the progress of time (i.e., a significant $Y \times$ Date effect, tested only in the Parents), no clear trend of increasing or decreasing hue angle over time was observed for either set of leaves, nor when both sets of leaves were combined (no significant overall Date effect, Table 2). The genotype $\times$ rootstock effect (tested only in the progeny populations) indicated that some progeny genotypes had a significantly increased hue angle when grown on the 'Nemaguard' rootstock compared to on their own roots, while others had a lower hue angle on 'Nemaguard', which may also be interpreted as just random variation between genotype replicates. However, there was no general effect of the 'Nemaguard' rootstock on senescent leaf hue angle (Table 2).

\section{Discussion}

The results of this study are consistent with the hypothesis that the $Y$ locus of peach pleiotropically controls fruit flesh color, senescent leaf color, and inner hypanthium color. Qualitative assessment easily identified the clear relationship between these traits, with complete co-segregation observed in two related progeny populations and maintained in a set of genetically variable cultivars. Thus, $Y$ is probably the same locus as $L F C L R$, which was previously only indicated by comparative mapping (Bliss et al., 2002). Each trait was inherited in a simple dominant manner, with white fruit flesh, yellow senescent leaves (hue angle of 81-91), and yellowish inner hypanthia being the dominant phenotypes. Observations of hypanthium color were in dispute with a codominant inheritance system purported by Connors (1923). The latter suggested that hypanthia with a yellow cream to yellow buff color are found in white-fleshed individuals that are heterozygous at the $Y$ locus, and therefore differentiated from the green, white, or pale cream hypanthia associated with homozygous white-fleshed genotypes, with deep orange hypanthia occurring in genotypes with yellow-fleshed fruit (recessive homozygous at the $Y$ locus). Although qualitative differences in hypanthium color were entirely associated with the $Y$ locus (Table 1 ), all white-fleshed genotypes (Pop-G includes heterozygous and homozygous types while all of Pop-DG is heterozygous) had yellowish hypanthia. Pale colored hypanthia were not observed in mature flowers. While the observation of codominant inheritance for the $Y$ locus would be advantageous to peach breeders and geneticists, it appears that this cannot be achieved with qualitative 

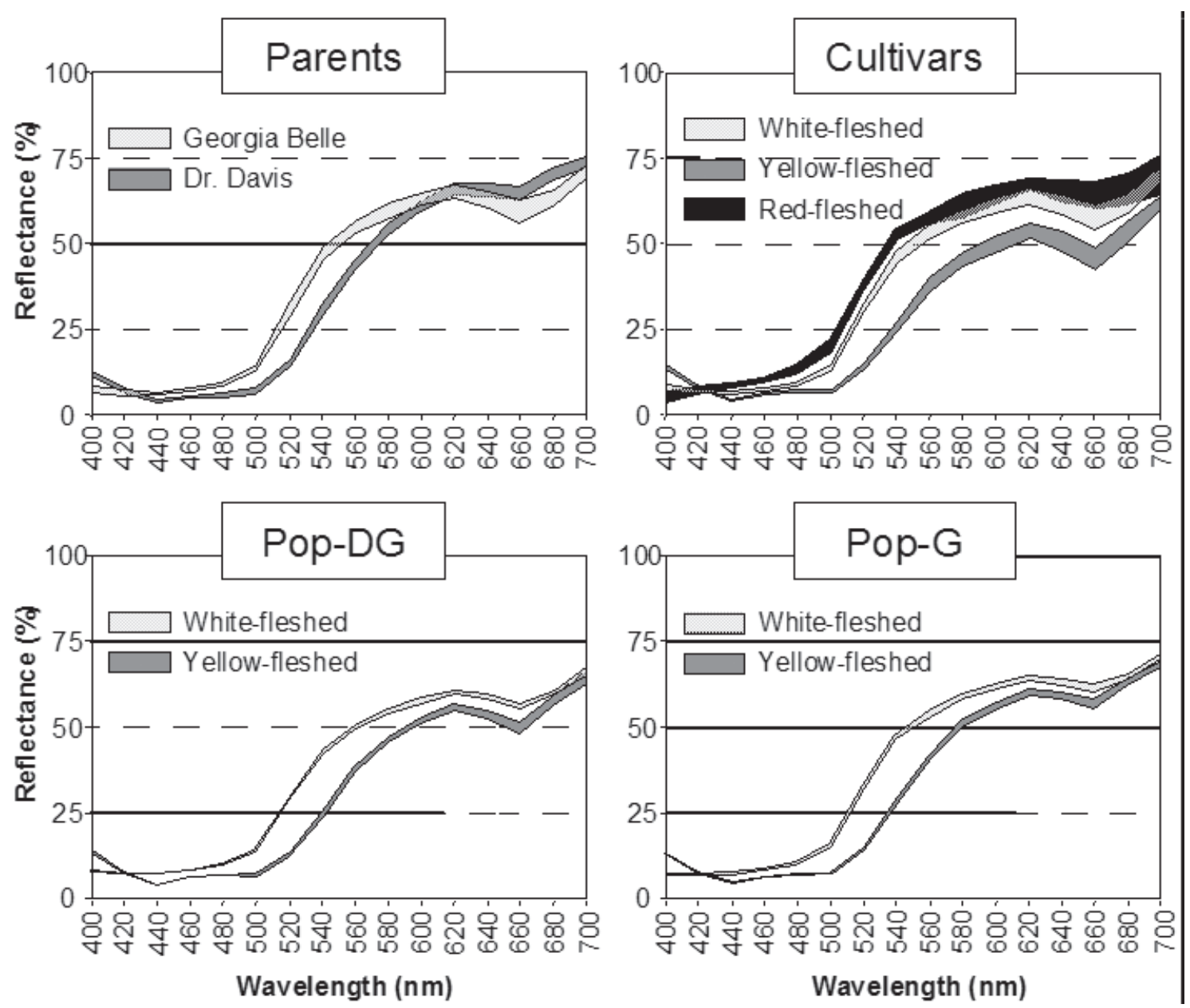

Fig. 3. Reflectance curves for senescent leaves of white- and yellow-fleshed peach trees in four germplasm sets (values for leaves of a red-fleshed cultivar are also shown for Cultivars). The filled-area curves for each flesh type show the $99 \%$ confidence interval either side of the mean. Parents $=$ white-fleshed cultivar Georgia Belle and yellow-fleshed cultivar Dr. Davis; Cultivars $=10$ white-fleshed cultivars and 10 yellow-fleshed cultivars; Pop-DG $=51 \mathrm{~F}_{1}$ progeny of 'Dr. Davis' $\mathrm{X}$ 'Georgia Belle'; Pop-G = 64 progeny from selfing 'Georgia Belle'.

Table 2. Effect ( $\mathrm{F}$ value) of various factors on hue angle of senescent leaves, as determined by ANOVA using a general linear model containing the listed factors for each peach germplasm set.

\begin{tabular}{|c|c|c|c|c|c|c|c|c|c|}
\hline$\overline{\text { Germplasm }^{z}}$ & $\mathrm{Y}^{\mathrm{y}}$ & Gen $^{y}$ & $\operatorname{Gen}(w)^{y}$ & Gen $(y)^{y}$ & Date $^{y}$ & $\mathrm{Y} \times$ Date & Rtstk $^{y}$ & $\mathrm{Y} \times$ Rtstk & $\mathrm{G} \times$ Rtstk \\
\hline Parents & $783^{* *}$ & - & - & - & $2.5^{\mathrm{NS}}$ & $5.5^{* *}$ & - & - & - \\
\hline Cultivars & $653^{* *}$ & $54.7^{* *}$ & $4.7^{* *}$ & $3.3^{* *}$ & - & - & - & - & - \\
\hline Pop-DG & $4519^{* *}$ & $122^{* *}$ & $3.6^{* * *}$ & $4.2^{* * *}$ & - & - & $0.3^{\mathrm{Ns}}$ & $1.4^{\mathrm{Ns}}$ & $2.6^{* *}$ \\
\hline Pop-G & $3367^{* * *}$ & $85.8^{* *}$ & $9.8^{* *}$ & $5.4^{* *}$ & - & - & $2.1^{\mathrm{Ns}}$ & $0.1^{\mathrm{ss}}$ & $4.1^{* *}$ \\
\hline
\end{tabular}

"Parents $=$ white-fleshed cultivar Georgia Belle and yellow-fleshed cultivar Dr. Davis; Cultivars = 10 white-fleshed cultivars and 10 yellow-fleshed cultivars; Pop-DG = 51 F progeny of 'Dr. Davis' x 'Georgia Belle;' Pop-G = 64 progeny from selfing 'Georgia Belle'. yY = flesh color locus; Gen = genotype; Gen $(\mathrm{w})=$ genotype within white-fleshed individuals only; Gen $(\mathrm{y})=$ genotype within yellowfleshed individuals only; Date $=$ date of leaf harvest; Rtstk $=$ rootstock.

Ns, **Nonsignificant and significant at $P<0.01$, respectively; $-=$ effect not tested.

assessment of color of fruit, senescent leaves, or hypanthia, nor with quantitative measurement of senescent leaf color, within the germplasm assessed. While senescent leaves of the red-fleshed cultivar were most similar to those of white-fleshed cultivars, values were at or beyond the extremes of white-fleshed fleshed cultivars. Colorimetric analysis of senescent leaves of further red-fleshed cultivars would verify whether this is a consistent phenomenon. The red-flesh phenotype may be controlled by a third allele at the $Y$ locus or a separate gene whose effects extend to senescent leaf color. Control by independent loci suggests the possibility of an unusual flesh color when major red pigmentation and yellow flesh are combined in one individual. Observation of flesh color inheritance in crosses between heterozygous white- and red-fleshed types is required to resolve this issue.

Breeders may readily exploit the pleiotropy of the $Y$ locus when selecting for progeny with either white or yellow flesh. Some of the first attempts that were made to predict fruit flesh color involved observing inner hypanthium color (Connors, 1919), although this trait can only be recorded at reproductive maturity. The possible link between flesh color and senescent leaf color was reported later (Hofmann, 1940; Moore, 1948). The present study confirms that senescent leaf color and hypanthium color are accurate indirect selection criteria for flesh color. While quantification of senescent leaf color using colorimetric analysis 
showed that the highly correlated traits of hue angle and 520 $\mathrm{nm}$ reflectance were the parameters most affected by flesh color (Fig. 1), value ranges for these two parameters within white- and yellow-fleshed genotypes were so well separated (Fig. 2) that qualitative categorizing is easily achievable based on colorimetric analysis of a single leaf, or more simply, visual assessment. Observation of leaves is particularly practical as it should be scorable in seedlings during the first fall season, allowing rapid and early screening of segregating populations. In fact, we have observed that the yellow/orange differentiation can be seen in leaves senescing at any time of the year, as suggested by Hofmann (1940). Anyone with this knowledge can walk through a flesh color-variable collection of peach plants in a nursery or orchard and readily determine flesh color. Although senescent leaves of the one red-fleshed cultivar tested here appeared yellow to the naked eye and was therefore identical to white-fleshed individuals, if necessary, flesh color (red, white, or yellow) could be verified colorimetrically by recording reflectance values at 440 to 540 $\mathrm{nm}$, particularly at $520 \mathrm{~nm}$.

The $Y / L F C L R$ locus probably represents a gene that is part of the carotenoid biosynthesis/degradation pathway. Identifying this gene could provide useful information on the regulation of carotenoids in fruit, and a DNA test for breeders. Identification and quantification of carotenoids in peach fruit and leaves provide support for this idea. White-fleshed cultivars have the lowest content of $\beta$-carotene (an orange pigment) in fruit and leaves, whereas cultivars with yellow and especially darker yellow/orange fruit contain high levels of $\beta$-carotene in their fruit and leaves (Ackerman and Hough, 1950; Morrison, 1990). Total fruit carotenoid and $\beta$-carotene concentration is greater by a factor of about 10 in yellow-fleshed compared to white-fleshed peaches and nectarines, and another carotenoid, the yellow pigment $\beta$-cryptoxanthin, is usually higher in the fruit flesh of yellow-fleshed cultivars (Gil et al., 2002). An extra chromatographic band, yellow in color and possibly representing isolutein, was identified in the fruit and green leaves of yellow-fleshed cultivars but not white-fleshed cultivars, and together with differences in carotenoid concentration, probably accounted for the different reflectance curves for the two types of cultivars (Ackerman and Hough, 1950). Reflectance curves of white- and yellow-flesh types observed in the present study (Fig. 3) were very similar to those of Ackerman and Hough (1950), therefore likely reflecting qualitative and quantitative carotenoid differences. In genetic terms, presence of the dominant allele results in a lack of orange pigmentation in leaves and a lack of any pigmentation in fruit. This suggests that the gene represented by $Y$ controls the degradation of one or more specific carotenoids, or a step in the carotenoid biochemical pathway that leads potential precursors away from these compounds. As such, the $Y$ locus of peach is unlike the $y l$ locus of maize (Zea mays L.) or the $R$ locus of tomato (Lycopersicon esculentum Mill.), both of which represent phytoene synthase (Buckner et al., 1996; Fray and Grierson, 1993). In these cases, the recessive mutants are lighter-colored and lacking carotenoids, as the compromised enzyme is a critical upstream regulator of carotenoid synthesis. A candidate gene approach focusing on yellow-orange carotenoid degradation enzymes may be an efficient means to identify the $Y$ locus gene.

\section{Literature Cited}

Ackerman, W. and L. Hough. 1950. Determination and correlation of leaf and fruit pigments of yellow and white flesh peaches. Proc. Amer. Soc. Hort. Sci. 56:157-163.

Bailey, J.S. and A.P. French. 1949. The inheritance of certain fruit and foliage characters in the peach. Bul. Mass. Agr. Expt. Sta. 452:2-31. Bliss, F.A., S. Arulsekar, M.R. Foolad, V. Becerra, A.M. Gillen, M.L. Warburton, A.M. Dandekar, G.M. Kocsisne, and K.K. Mydin. 2002. An expanded genetic linkage map of Prunus based on an interspecific cross between almond and peach. Genome 45:520-529. Buckner, B., P. San Miguel, D. Janick-Buckner, and J.L. Bennetzen. 1996. The y1 gene of maize codes for phytoene synthase. Genetics 143:479-488.

Connors, C.H. 1923. Peach breeding-A summary of results. Proc. Amer. Soc. Hort. Sci. 19:108-115.

Connors, C.H. 1919. Some notes on the inheritance of unit characters in the peach. Proc. Amer. Soc. Hort. Sci. 16:24-36.

Fray, R.G. and D. Grierson 1993. Identification and genetic analysis of normal and mutant phytoene synthase genes of tomato by sequencing, complementation and co-suppression. Plant Mol. Biol. 22:589-602.

Gil, M.I., F.A. Tomas-Barberan, B. Hess-Pierce, and A.A. Kader. 2002. Antioxidant capacities, phenolic compounds, carotenoids, and vitamin $\mathrm{C}$ contents of nectarine, peach, and plum cultivars from California. J. Agr. Food Chem. 50:4976-4982.

Hofmann, F.W. 1940. Foliar characters for peach breeding. Virginia J. Sci.1:208-209.

Moore, R.C. 1948. Peach leaf color as an indicator of fruit flesh color. Proc. Amer. Soc. Hort. Sci. 51:216-218.

Morrison, D.M. 1990. Color and beta-carotene in six genotypes of peach. MS thesis, California State Univ., Fresno.

Okie, W.R. 1998. Handbook of peach and nectarine varieties: Performance in the southeastern United States and index of names. U.S. Dept. of Agr., Agr. Hdbk. No. 714.

Schery, R.W. 1972. Plants for man. Prentice Hall, Englewood Cliffs, N.J.

U.S. Department of Agriculture. 2005. California tree fruit packout for September 26, 2005. Western Fruit Rpt. 13:2.

Voss, D.H. 1992. Relating colorimeter measurement of plant color to the Royal Horticultural Society Colour Chart. HortScience 27:12561260 . 